Original paper

\title{
The Flood Resilience Systems Framework: from Concept to Application
}

\author{
Piotr Magnuszewski ${ }^{1,2}$, Lukasz Jarzabek ${ }^{2}$, Adriana Keating ${ }^{1}$, Reinhard Mechler ${ }^{1}$, \\ Adam French $^{1}$, Finn Laurien', Miguel Arestegui ${ }^{3}$, Emilie Etienne ${ }^{3}$, Lili Ilieva ${ }^{3}$, Pedro \\ Ferradas $^{3}$, Colin McQuistan ${ }^{4}$, Beatriz Mayor ${ }^{1,5}$
}

Received: 06/04/2018 / Accepted: 09/01/2018 / Published online: 08/08/2019

\begin{abstract}
Disaster risk is on the increase, burgeoning due to development drivers and barriers to effective risk management. There is an urgent need to understand and effectively tackle these drivers within the disaster-development system. Resilience is a concept with its roots in systems analysis, which if embraced can foster the transformative change needed to meet this challenge. This paper demonstrates how the Flood Resilience System Framework (FLORES) has been operationalized in the form of three distinct tools: a qualitative model that specifies causal connections between the framework elements, a stylized quantitative dynamic model of household flood resilience, and the Flood Resilience Game that works as an interactive, handson introduction to the framework. The paper also describes how these tools were implemented in multi-stakeholder workshop in Peru, Indonesia, and Spain.
\end{abstract}

Key words Disaster resilience; Systems analysis; Disaster risk management.

\section{INTRODUCTION}

It has been widely recognized that natural disasters are all but natural. In 1945, Gilbert White identified the role of socio-ecological factors in shaping disaster risk, when he argued, "floods are an act of God, but flood losses are largely an act of man" (White 1945). There has been widespread recognition over the years that disaster risk is in fact 'unnatural', i.e. shaped by the interaction of human agency (exposure and vulnerabilities of people and assets) with hydrometeorological and geophysical phenomena. This understanding has led to calls to replace a response-oriented stance with one characterized by proactive risk management in policy and action generally, and the management of extreme events specifically (Beck 1992;

\footnotetext{
${ }^{1}$ International Institute for Applied Systems Analysis, Austria.

${ }^{2}$ Center for Systems Solutions, Poland.

${ }^{3}$ Soluciones Prácticas, Peru.

${ }^{4}$ Practical Action, United Kingdom.

5 iCatalist, Spain.
} 
Klinke and Renn 2002; Linnerooth-Bayer et al. 2005; World Bank and UN 2010). At the same time, it has been widely recognized that risk management will be insufficient to arrest increases in risk (e.g. Hochrainer-Stigler et al. 2017); addressing the underlying developmental drivers shaping risk is required (Keating et al. 2017).

The passing of the Sustainable Development Goals in 2015, constituting a universal set of seventeen goals and 169 targets defining transformative development aspirations for all signatory countries collectively (SDSN 2015), has given additional impetus to the need for a change in approach. There is a need to move towards transformative risk management that emphasizes incentives for enhancing risk reduction, avoiding risk creation and generating additional developmental co-benefits (see Mechler et al. 2018). As another key source, the Global Assessment Report 2015 (UNISDR 2015) identifies integrating disaster risk reduction efforts with intersectoral sustainable development actions as a key challenge for the disasters field. Achieving that goal would require "a combination of prospective risk management to ensure that risks are appropriately managed in new investment, corrective risk management to reduce the risk present in existing capital stock, and compensatory risk management to strengthen resilience at all levels" (UNISDR 2015, p. xviii). In short, tackling increasing disaster risk requires that it be considered far beyond the traditional disaster risk management (DRM) remit. Instead it should be incorporated into decision-making right across society at all levels.

These calls for a broader, systems-wide approach to tackling disaster risk are being echoed by practitioners engaged in the humanitarian and development sectors (Mitchell 2013; Keating and Hanger, forthcoming). A key challenge identified and to be addressed by the development sector is the fact that disasters can wash away years of hard work by a community in seconds. The charge for the humanitarian sector, on the other hand, is to meet the urgent needs, help the community to get back on track and rebuild livelihoods. Unfortunately, in practice this has often meant rebuilding pre-existing vulnerabilities rather than building back better. Therefore, the challenge is to usefully embed DRM into community development, in a way that is sustainable in the long-term, while at the same time facilitating communities to make choices about their future development that do not create more risk (see figure 1 for a stylized example on flood risk).

Of course, large-scale disasters such as floods cannot fully be avoided, but measures can be taken to ensure they do not erode hard-earned development gains. Overall, the charge recognized in research, policy and practice is to better learn to be disaster resilient in terms of identifying and taking action where risk can be reduced (and not created) and development enhanced in mutually reinforcing ways (Keating et al. 2017). This involves considering transformational change as part of risk management responses. Learning to live, and thrive, with disaster risk may concretely mean considering disaster risk in planning and investment decisions right from inception, as well as implementing steps to protect assets already at risk. It also involves planning for response and recovery to protect and even enhance individual and community development potentials. Emerging evidence exists that these challenges can indeed be tackled in tandem, yet more reflection and insight is needed to robustly support ongoing shifts in thinking and implementation (see Mechler et al. 2018). 


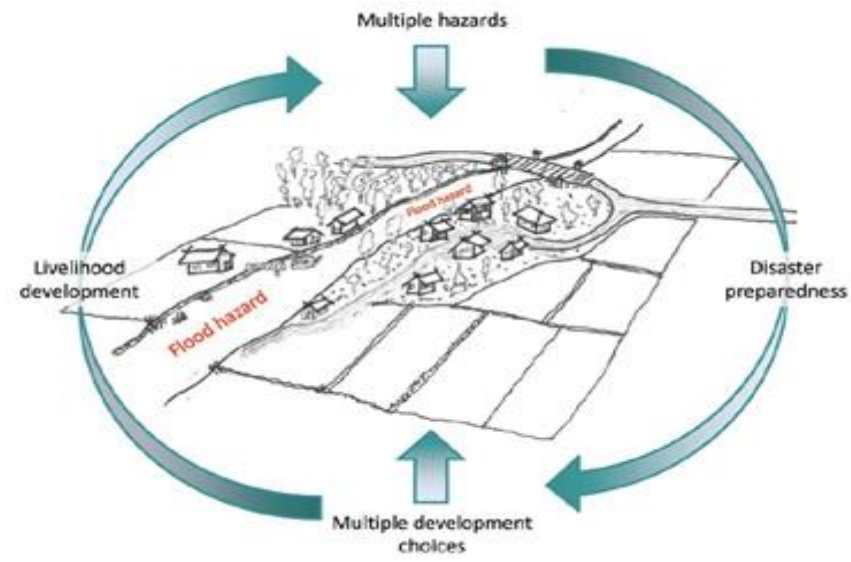

Figure 1. The practice imperative - connecting disaster preparedness and livelihood development. (Source: McQuistan 2015)

A shift towards a more holistic or systems-based approach is a challenge for the DRM field; dominant approaches to understanding and addressing disaster risk are reductionist in that they are disconnected from developmental drivers and impacts. As a result, existing methods and tools may not be appropriate or adequate. To support this shift and service the varied decisionsupport demands from policy and practice, a closer examination of the interconnections between disasters and development within complex socio-ecological systems is needed. We argue that one potential way forward is to explore the usefulness of the concept of disaster resilience and methods as part of a systems perspective. This need is echoed by demand from the development sector to embrace the concept of disaster resilience, especially the systems analysis that forms the foundation for the concept. Recent research (Keating and Hanger, forthcoming) indicate that not only do practitioners view resilience as having the potential to integrate development and DRM, they see this as fundamentally transformative.

The paper reports on a systems-thinking approach to exploring the concept of disaster resilience. After discussing the history and evolution of the concept of resilience in section 2, in section 3 we present our Flood Resilience System (FLORES) framework which interlinks disaster risk, disaster risk management, and development and wellbeing, and identifies transformative risk management strategies.

We then describe how the framework has been translated into our methodological approach including applied methods and tools in section 4. These applications include qualitative systems modeling to tackle flood risk in Peru, a stylized dynamics model, and the Flood Resilience Game. In particular, the game has resonated well with practitioners and local policymakers, and we present learnings from a number of applications. The final section summarizes our exploration of the resilience space using systems analysis.

\section{RESILIENCE AND SYSTEMS ANALYSIS: BACKGROUND}

\subsection{History of the Concept of Resilience, Focus on Systems Analysis Roots}

The term 'resilience', introduced by C. S. Holling (1973), refers to the ability of a system to withstand disturbance: absorbing the impacts of shock and reorganizing afterwards (Walker et al. 2004). Folke (2006), describes the historical emergence of the resilience perspective, 
bringing forward its roots in system dynamics modeling techniques. The approach highlighted how social and ecological systems are mutually interdependent, in opposition to thenmainstream ecology that perceived human activities as external from ecosystems.

Nowadays, increasing popularity of the resilience concept in different fields results in the many ways it is defined. In the business context, for example, it is defined as an ability of company to adjust in a continuous manner to the turbulences caused by rapidly changing world (Rydzak et al. 2006; Horne 1997; Hamel and Välikangas 2003). Some use the term to describe an ability to deal with personal stress and misfortunes (Coutu 2002). The concept still evolves, and it is being applied to broad spectrum of disciplines, including policy, development, security, cooperation, politics, and transformation.

To assess resilience of a particular system, three of its characteristics should be considered: how much change the system can undergo without changing its structure and functions; the capability of a system to self-organize; and the capacity of a system to learn and adapt (Carpenter et al. 2001; Walker et al. 2002). Carpenter et al. (2001) further argue that in order to make the concept of resilience meaningful, one needs to answer the questions of what system state is being considered ('resilience of what') and what disturbances are of interest ('resilience to what').

As resilience to disturbance can be a characteristic of both desirable and undesirable states of a system, the resilience concept should be considered as value-neutral (Fabinyi et al. 2014). Poverty and inequality, in this example, can be at the same time resilient and pathologic (Carpenter et al. 2001). Béné et al. (2014) go even further, arguing that the resilience concept is "poor-neutral" and not "pro-poor", also emphasizing the need for better understanding of the resilience concept, careful recognition between desirable and undesirable resiliencies, and including the agency and power dimensions in resilience analysis.

The need for transformation follows the recognition of "pathological resilience". Folke (2006) emphasizes that although most resilience discourse focuses on the aspect of "maintaining systems functions in the face of shocks", it is also important to define a system's resilience through its capacity for renewal, re-organization, and development, which is crucial when we place the resilience discourse in relation to the field of sustainability. Following Adger (2006), Folke argues that while disturbances in a vulnerable system lead to tragedies, in a resilient system, a disturbance can create an opportunity for positive change.

Furthermore, the concept of transformability proposed by Walker et al. (2004) describes the potential for a deliberate shift from an undesirable current attractor to a new one with a new stability landscape. Olsson et al. (2006, p. 18) provide a further definition of transformability as the capacity to define and create "novel system configurations by introducing new components and ways of governing social-ecological systems (SES), thereby changing the state variables, and often the scales of key cycles, that define the system. Transformations fundamentally change the structures and processes that alternate feedback loops in SESs." A critical initial step is to assess the feasibility of such transformation (Olsson et al. 2006; Gunderson 1999, 2003).

Is there sufficient adaptive capacity and integrity within the system to support navigation from one management regime to another?

A systems approach to development and change is crucial in resilience thinking, as Walker and Salt (2006, p. 14) emphasize, arguing that one of the key points of resilience is finding an alternative to development practices that are focused on "increasing efficiency and optimizing performance of the parts of social-ecological systems that deliver defined benefits", but at the 
same time fail "to acknowledge secondary effects and feedbacks that cause changes (sometimes irreversible changes) in the bigger system, including changes to unrecognized benefits". Such focus on the efficiency of specific parts of systems, coupled with neglect of how systems respond, instead of resulting in development gains, can lead to economic collapse (Walker and Salt 2006).

\subsection{The Rise of Resilience in the Disasters Field}

The rise of popularity of resilience in the disasters field corresponds with how the perception of disasters changed from Acts of God/Nature to consequences of vulnerability (Manyena et al. 2011). A recent shift in thinking about disasters observed in major publications on DRM such as Sendai Framework for Disaster Risk Reduction 2015-2030 (United Nations 2015) and the Global Assessment Report 2015 (UNISDR 2015) goes even further, seeing disasters as a part and consequence of development, rather than external threats to development achievements. Disasters should be then treated as "socially constructed inside development" (UNISDR 2015), and disaster risk reduction should be an inherent element of development efforts, "making nations and communities resilient to disasters" (United Nations 2015).

In recent years, the concept of resilience has been employed by the disaster community as a lens through which the relations within socio-ecological systems that create disasters can be analyzed and understood. Key examples include the contexts of river (Sendzimir et al. 2007) and coastal (Adger et al. 2005) flooding, but also other types of disasters such as toxic waste, environmental degradation and volcanic hazards (Paton and Johnston 2001), or earthquakes (Bruneau et al. 2003).

One exemplary and widely cited definition comes from the UNISDR, which states that resilience is ,the ability of a system, community or society exposed to hazards to resist, absorb, accommodate, adapt to, transform and recover from the effects of a hazard in a timely and efficient manner, including through the preservation and restoration of its essential basic structures and functions through risk management" (UNISDR, 2009). An analysis of this and a number of other definitions of disaster resilience proposed by academics, donor organizations, and practitioners from the field (Keating et al. 2017) showed that most of the analyzed definitions recognize the importance of disaster risk management with emphasis on risk reduction aspects; many definitions also included a continuous development aspect, with some of them also hinting at the importance of wellbeing.

Based on analyzed definitions and current shifts in the thinking about relations between disaster risk management and development, Keating et al. (2017, p. 19) propose a definition of disaster resilience that builds on existing ones, including the UNISDR's definition, while putting explicit emphasis on human wellbeing: "The ability of a system, community or society to pursue its social, ecological and economic development objectives, while managing its disaster risk over time in a mutually reinforcing way". Placing wellbeing instead of hazards in the center of this disaster resilience definition is motivated by growing demand from scholars, policy makers and practitioners, and is built on an assertion that human wellbeing is the eventual goal for both development and DRM efforts. 


\section{CONCEPTUALIZING FLOOD RESILIENCE FOR TRANSFORMATIVE RISK MANAGEMENT: BUILDING THE FLORES METHODOLOGICAL FRAMEWORK}

Based on Keating et al.'s (2017) definition, which centralizes enhancing human wellbeing as the ultimate goal of both DRM and development, we now proceed to present the building blocks of the FLORES conceptual framework for understanding the disaster-development system and operationalizing insights with stakeholder.

\subsection{Sustainable Livelihoods Framework and Household Economy Approach}

Notions of capacities and capital are fundamental for the genesis of the FLORES framework. For these, we strongly build on the Sustainable Livelihoods (SL) framework and the Household Economy Approach (HEA). The SL framework is a holistic framework for conducting livelihood analysis in rural developing countries. Its underlying concept is based on the entitlement theory (Sen 1981), which considers a causal relationship between shocks (disasters or other disruptions) and the contextual change of households' wellbeing (people are unable to meet their food entitlement) (Scoones 1998). The theory assumes that households are constrained by the initial endowment (labor or livestock), the ability to produce other capitals (food, assets or income) and external conditions (such as social, market and institutional conditions) at the time a shock has happened.

Drawing on the entitlement theory the SL framework represents a wider range of livelihood resources which depend on basic material and social, tangible and intangible assets that is in the household's possession. The SL framework has identified five different capitals for empirical investigation (Scoones 1998; DFID 2001):

- Natural capital - natural resource stocks and eco-services which are useful for livelihoods and resource flows;

- Financial capital - economic assets and other production utilities which are essential for pursuit any strategy for livelihoods;

- Human capital - any capacity building including the ability to labor and good health for a successful pursuit of different livelihood strategies;

- Social capital - any resource associated with social capacities, such as networks, social relations or social claims;

- Physical capital - basic infrastructure and physical goods that support livelihoods.

The household's endowment is defined by a combination of these capitals which enables them to create livelihood outcomes by implementing different livelihood strategies that produce wellbeing, open opportunity and enable risk management (Scoones 1998; DFID 2001). From a practical perspective, the framework has been applied in project-based studies in rural communities in developing and developed countries at multiple scales (Keating et al. 2017).

The Household Economy Approach (HEA) is a framework for analyzing the economic conditions of households in a comparable way across geographical regions and socio-economic 
groups. The approach is an empirical and rather flexible framework to sufficiently meet the pragmatic requirements for practitioners such as NGOs. The approach has been applied in a range of different settings, demonstrating its effectiveness in conducting comparable and empirical analysis of the economic and development situation of households (Brown 2015).

The general focus of the HEA is to assess how households gain access to food and income under economic and environmental changes, and how their livelihoods are affected by these changes. Thus, the HEA measures the changes in the annual food energy needs for households. As shown by Holzmann (2008) the approach includes a threshold concept which applies at two threshold levels: a survival threshold and livelihood-protection threshold.

In a next step, the HEA uses a model-based approach to undertake a baseline analysis and an outcome analysis. The baseline analysis represents a picture of the annual normal household economy without unusual shocks or disturbances. It includes a livelihood pattern analysis (zoning), wealth breakdown and analysis of livelihood strategies for each wealth group. The outcome analysis assesses the possible changes in food access and income by investigating a hazard specification (problem specification), analyzing the coping capacity and building scenarios for projected outcomes (Holzmann 2008). As a result of the analysis, economic impacts of hazards on food and income sources are assessed and the quantification of common coping strategies for households are identified (also across different income groups).

The measurement of two threshold levels with a baseline scenario and a projected outcome scenario is a valuable aspect for practitioners in the operating region, since they get information of the socio-economic endowment of households in their communities which comparable quantitative results. However, the HEA also looks into the types of hazards to understand the coping strategies of different household income groups. The summary of both the socioeconomic endowments of households and the types and severity of hazards in the region are then used to provide near to mid -termed solutions on a broader community scale. All these useful and available components of a HEA can be used to operationalize a system dynamics model to show also the more indirect consequences for the longer period.

\subsection{Building to the Flood Resilience System (FLORES) Framework}

After introducing the SL and HEA as formative to our resilience exploration, we now turn to describing the Flood Resilience (FLORES) Framework. FLORES proposed by Author et al. (2017) offers a systemic approach to understanding of the complex disaster-development system. The framework focuses on system interactions between development and wellbeing, disaster risk, and disaster risk management practices. While it was developed through collaboration with flood-prone communities and it is centered around flood risk at the community level, it can be generalized to different types of hazard and different scales.

The difference between a framework and a conceptual model (presented later in section 4) is that the former is more generalized, and the latter more operationalized. For example, a framework does not include variables, and simplifies some of the relations between the elements. One framework can be used as a basis to create many models; each of these models has then a bigger focus on particular situation to which it is applied: e.g. it identifies specific variables and elements that exist within particular system, and it examines more closely the interconnections between them, which connections, in effect, are represented in a more "messy" manner than in the framework. The framework was developed using the "concept maps" technique (Cañas et al. 2005; Novak and Cañas 2006). Note figure 2 below is a different configuration of the FLORES framework presented in Keating et al. (2017). 
The FLORES framework (see figure 2) draws from its authors' definition of resilience, centered around wellbeing (Keating et al. 2017). Its purpose is to provide stakeholders with a tool for exploring how disaster risk impacts development, how development decisions may increase or mitigate disaster risk, and how disaster risk management efforts can impact longterm development. FLORES combines components drawn from the disaster risk management cycle (prospective risk reduction or avoiding risk creation, corrective risk reduction, crisis preparedness, reconstruction, response/rehabilitation); and from the SL framework (5 capitals: natural, financial, human, social, physical).

The FLORES framework links DRM with sustainable development via following relationships:

- Starting with the flood event, the first need is to understand the flood event, and how the direct impact of the flood event is influenced by the physical vulnerability of the community and their exposure to the hazard.

- This direct impact will cause damage, with the scale and severity of the damage determined by the status of crisis preparedness, and more importantly identification of those individuals at the sharp end of the impact, e.g. those living closest to the river, in the lowest lying land, or in the weakest, single-story houses. Without adequate coping mechanisms, the direct damage determines the losses or indirect damages that subsequently occur.

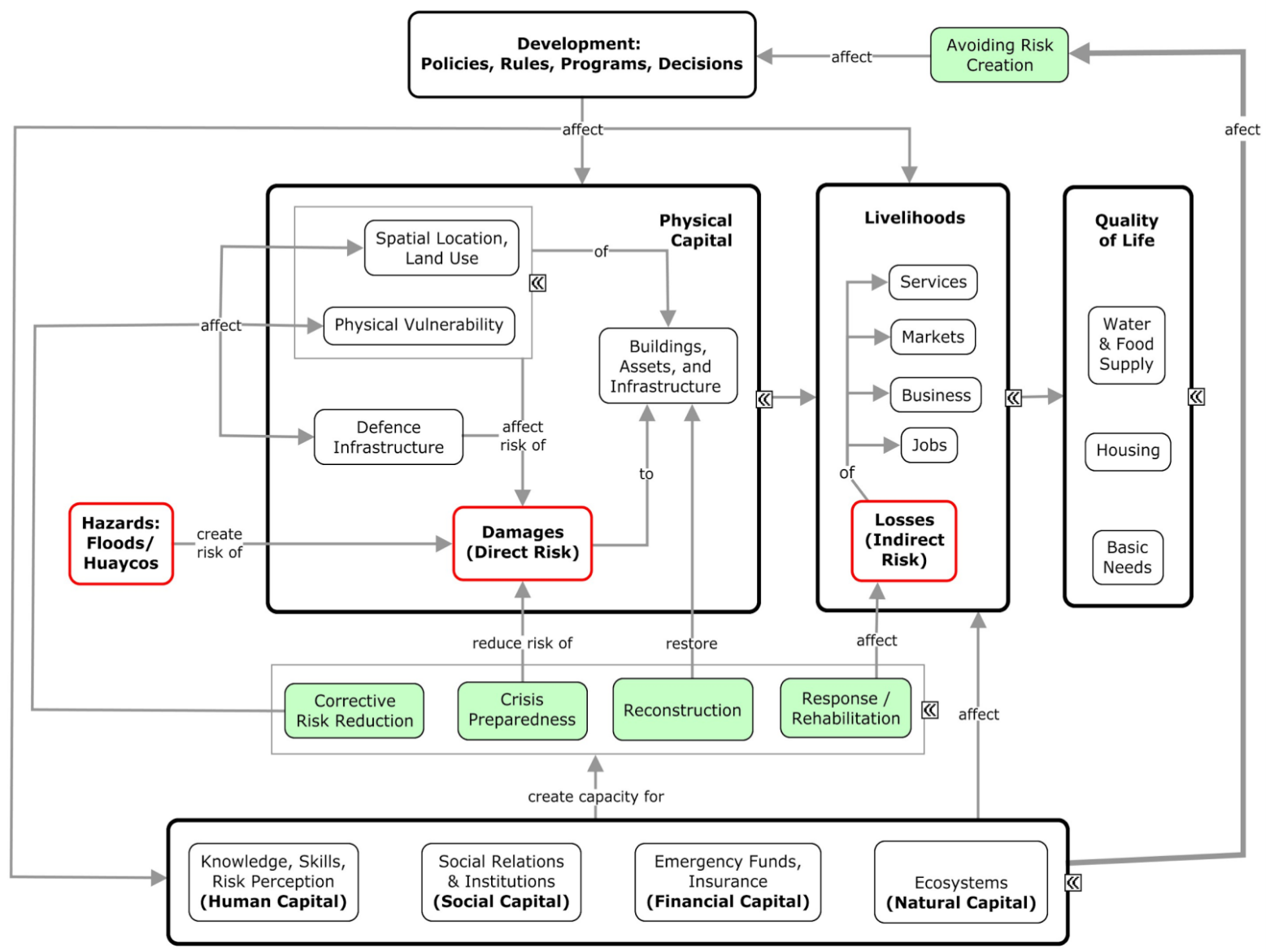

Figure 2. FLORES: flood resilience framework (elements of the DRM cycle are in green boxes; hazards, damages, and losses were marked with red borders for better clarity). 
- The sum of the direct and indirect damages and the recovery capacity of the community to respond to these damages will determine the impact on the community's wellbeing, and therefore affect their development trajectory. If the recovery capacity is weak, this will erode their development potential and slow or even reverse recent development gains.

- The community's access to knowledge and material resources will influence their risk awareness, risk-taking behavior, and perceptions of the future, directly affecting their aspirations and future targets. These less tangible but critical factors will influence the development choices that individuals make, and their investments in disaster risk preparedness and reduction measures.

- Individual levels of risk awareness and aspirations for the future will influence community development priorities going forward - the sum of these individual priorities will shape community actions on the ground, whether this is an individual landowner that lives next to the river building a flood defense, or the community asking the local (or even national) government for financing to build flood defenses.

- The communities' and local governments' perceptions of risk will enhance the corrective and prospective risk reduction measures, with experiences influencing local practice and with best practices captured to influence policies and guidelines.

- These measures will directly affect the community's physical vulnerability and exposure. This brings us back to the beginning of the FLORES framework; we cannot prevent the flood from happening, but we can reduce the community's physical vulnerability and exposure.

FLORES was presented to and consulted with stakeholders from different countries, with a more in-depth application in Peru. The response from the stakeholders highlighted the framework's realistic mapping of their intuitive knowledge (Keating et al. 2017), allowing them to systematize that knowledge, and laying ground for deeper understanding of how interconnections between disaster risk and development work, and what are best possible intervention points.

\section{APPLICATION OF THE FLOOD RESILIENCE SYSTEM FRAMEWORK: METHODS AND TOOLS}

The FLORES framework was a basis for a number of tools that aim to understand and improve community flood resilience. These tools range from system models to social simulation games that can be used for different purposes, depending on the application.

\subsection{Qualitative System Dynamics Modeling for System Level Integration of DRM And Development}

Conceptual modeling emerged to respond to the failure of quantitative systems analysis to cope with complex social-environmental problems (Magnuszewski 2010). Causal loop diagrams (Sterman 2000) are a qualitative systems tool that can be used for conceptual 
modeling. The first step in the modeling process is finding the variables of the analyzed system, and causal links between them. Then, feedback loops are identified, for example closed chains of causal connections. Causal loop diagrams can be employed to deal with common assumptions that causations are linear, providing a language that in an accessible manner uncovers circular patterns of causation between particular system elements (Magnuszewski 2010). Modeling methods are useful especially when the problem involves many people or organizations whose actions should be coordinated (Bertsche et al. 1996).

A qualitative system dynamics model (figure 3) of community flood resilience builds on a more general FLORES framework, representing more specific causal connections, and is intended as a first step to developing a quantitative model, which is even more specific.

The qualitative model defines a subset of variables and relationships that were not included in the FLORES framework, and focuses on household choices with respect to using their available budget (for the description of the variables see also Appendix C. Table listing the variables in Figure 3). Unlike HEA (that only features coping), this model broadens household responses with respect to the full spectrum of disaster risk management, including prevention measures (asset protection). Additionally, the model also broadens the perspective to include explicitly more variables representing different capitals conceptualized in the Sustainable Livelihoods framework. The model elaborates the financial capital aspect in comparison to the FLORES framework, specifically indicating interconnections between livelihoods, household budget, community budget, and funding sources. The model also shows how services availability impacts education level (part of human capital), which in turn impacts both job availability and quality of life.

Physical capital is divided into different elements (livelihood assets, infrastructure, defense infrastructure, houses), and the relations between each element and other parts of the model are also elaborated further in comparison to the framework (an example of how the conceptual model can specify internal relations between the elements of the framework is, for example, the infrastructure's impact on services availability presented in the model).

While the conceptual model further specifies the elements of the framework and relations between them, it is still relatively generalized. More in-depth analysis of different aspects of community flood resilience is possible with tools that build on the framework and the conceptual model: a simulation game and a stylized quantitative dynamic model. 


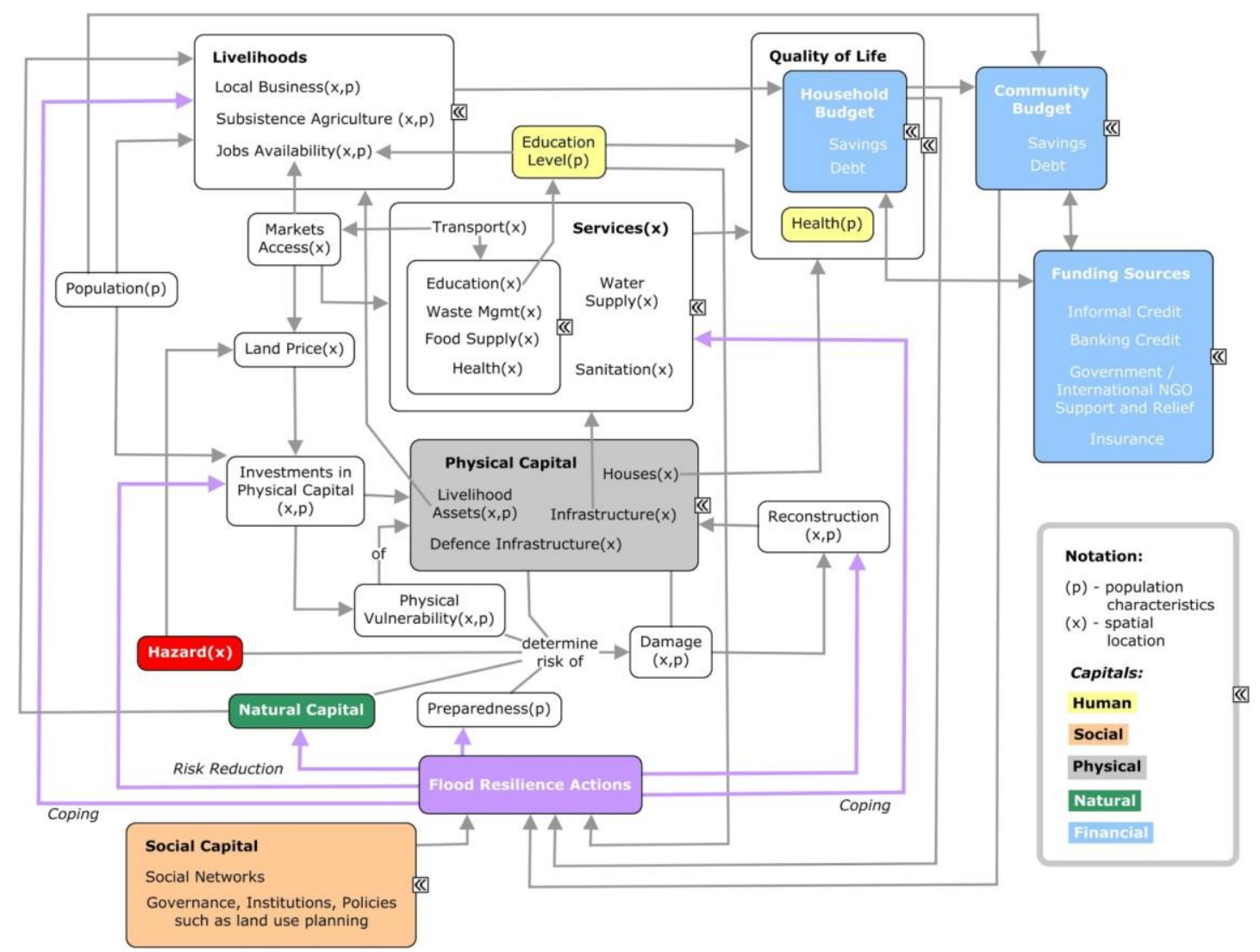

Figure 3. Conceptual model underlying the current and future more detailed models of community flood resilience (the impacts of Flood Resilience Actions' are marked in purple).

\subsection{Stylized dynamic model of household flood resilience}

The system dynamics model presented here provides a stylized representation of the flood risk and resilience related choices at the household level. In particular, this means that the proportions between the values of the variables in the model resemble real-life proportions, while the values themselves are stylized. Because of the focus on an individual household perspective, only the parts of the qualitative model that refer to single household decisions are examined closely and more detailed variables and interconnections referring to these decisions are identified.

The model builds on household expenditures pattern of the HEA with associated impacts from hazard mediated by coping. It includes the following improvements with respect to the standard HEA analysis:

- dynamic perspective added - change of the system in time (not only a static impact analysis),

- including prevention: added asset protection as a potential parallel priority for household budget spending,

- physical, human and social (in a rudimentary form) capitals are included.

The model can be used to discuss in a participatory way risk reduction or resilience building plans within stakeholder processes to enhance dialogue and collaboration. With many heuristics and biases clouding analysis and policy development in complex systems, system 
dynamics models can provide an additional reality check, as well as a common language for the stakeholders group to investigate best choices for different groups and individuals including their specific situation (Kahneman 2011). With a broader set of options including all elements of the disaster risk management cycle, the more rigorous process enhanced by the model use can lead to more informed decisions that better balance short- and long-term perspectives as well as the needs and objectives of different stakeholders. However, the model is currently still limited (as compared with the qualitative model of Figure 3), for example damages are only influenced by hazards, physical vulnerability and preparedness. Social, human, and natural capitals will also impact damages (for example: solidarity networks or green infrastructure may reduce damage) and most of these effects are not currently included.

The causal structure of the model is presented in figure 4. Budget choices result in specific outcomes that affect household budget (in the future) with many feedback loops. Numbers in the box with household budget priorities and allocation represent steps through which each budget is allocated. Lower numbers represent a higher priority. Additional letter (4a to $4 \mathrm{f}$ ) represent parallel priorities that can be further weighted. Agent choices regarding the household budget priorities and allocation impact other elements of the model: livelihoods income and assets that impact the household budget itself; and physical vulnerability that determines the risk of damage to the assets.

Depending on the budget availability and households' allocation priorities certain coping options, such as use of savings, or repair are more or less available.

The reduction of expenditures is always possible, however, depending on which spending is cut, it can lead to a downward spiral of declining resilience (e.g. when lower spending on education and health reduce human capital). Sustaining livelihoods should be a priority, however, in the event of a disaster, the funding sources may be not available, reducing incomes with dramatic consequences. Depending on the income level, debts can be either repaid and resilience restored, or debts can accumulate trapping households in a hopeless situation. Such scenario is likely especially with recurring hazards. The long-term solution of improving protection measures is not always possible due to limited funds. This suggests the importance of the external support as well as developing of human, social, and natural capital that can provide additional ways of building community resilience. Further work is needed to update the quantitative model to include other relationships and processes represented in the FLORES framework. 


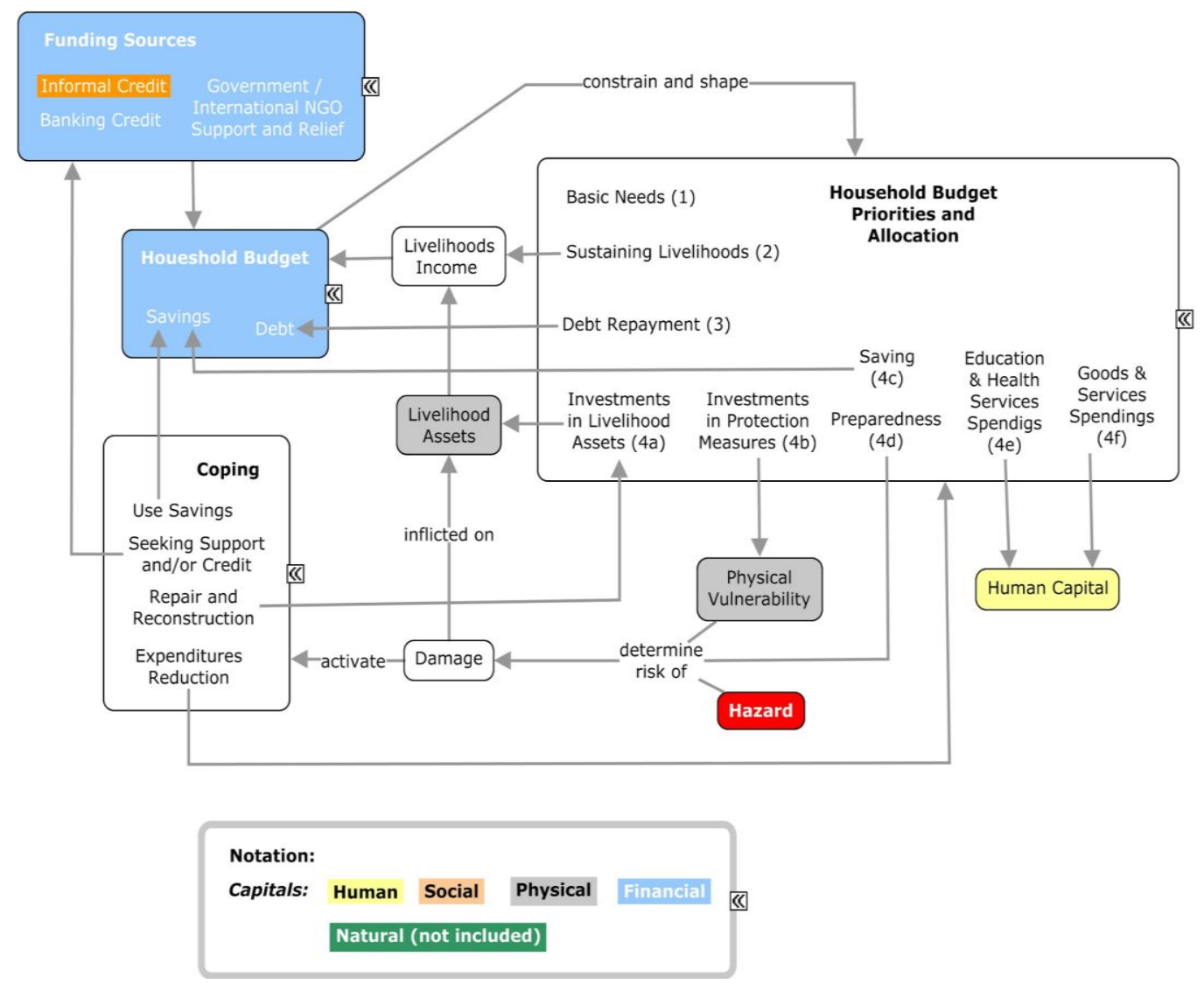

Figure 4. Causal relationships between the model variables.

\section{Model results}

For the purpose of visualizing resulting scenarios only most relevant variables were selected (see figure 5). The results presented on figure 5 represent a few scenarios (a combination of certain choices of model parameters) that provide first insights into the dynamics of household resilience. The initial conditions represent a typical low-income household that is not in a crisis, coping with normal circumstances. Such a household is challenged with a single disaster scenario and recurring disaster scenario.

Their responses depend on the given priority of actions (budget allocations) from figure 4. Even in a low-income household shifting some budget to prevention (protection measures) leads to better outcomes in the long term. In this stylized model we are not seeking to represent precise values of the variables. Rather, the model variables are represented as dimensionless indices with the intention to analyze its trends in a semi-quantitative way i.e. looking into their dynamic patterns: whether they increase, decrease, and how they react to disaster events. 
Scenario: single disaster

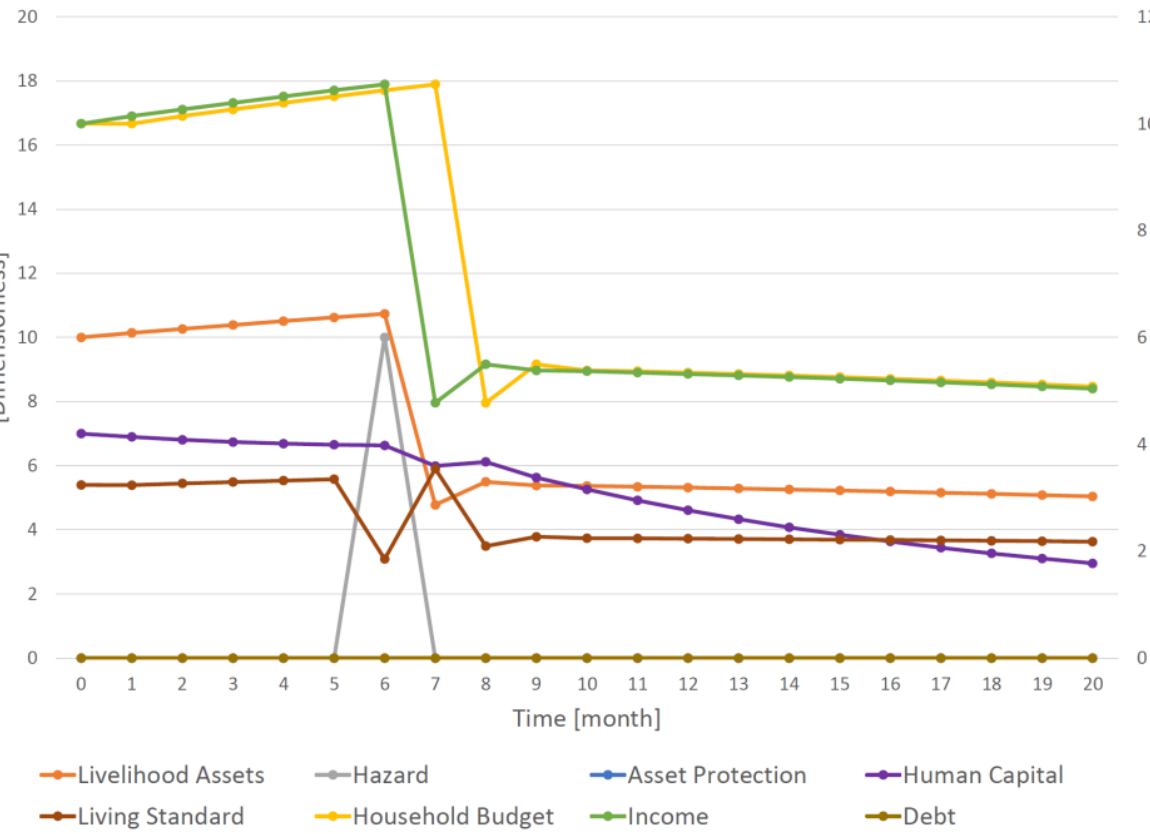

a) Single Disaster

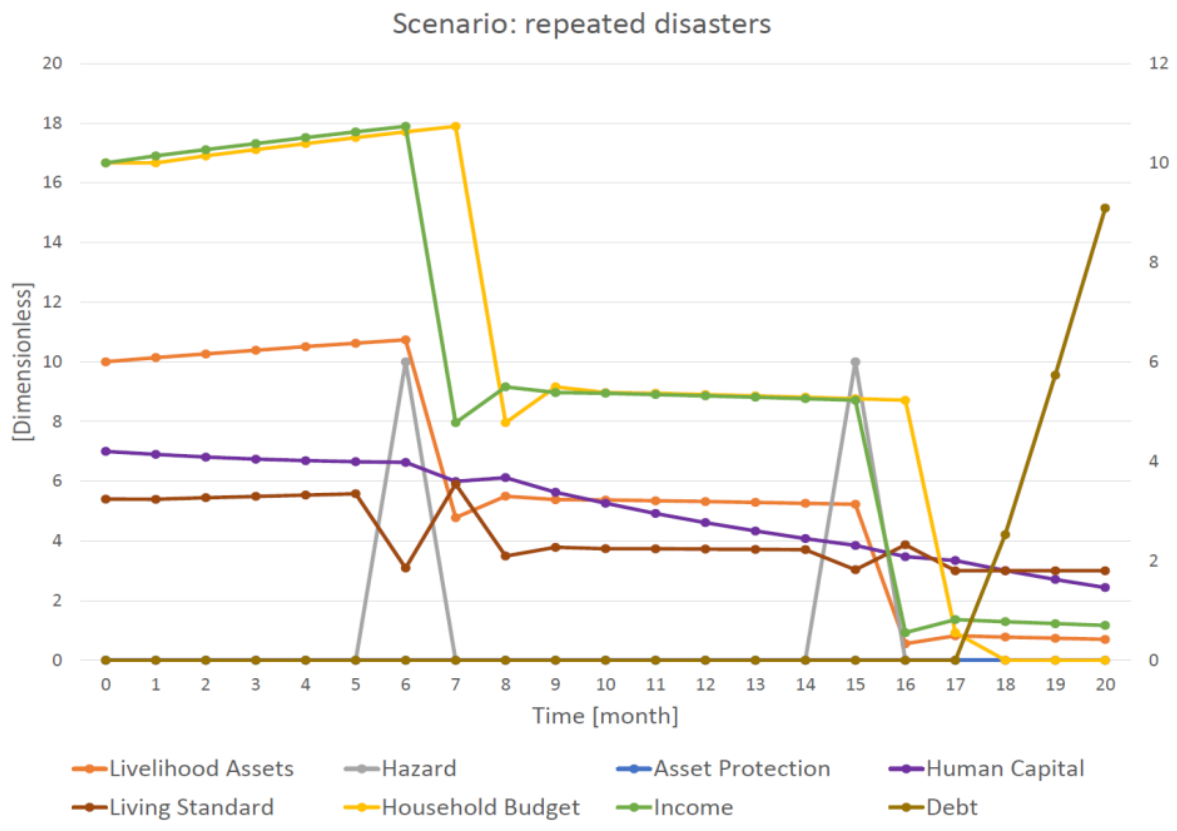

b) Repeated Disasters 


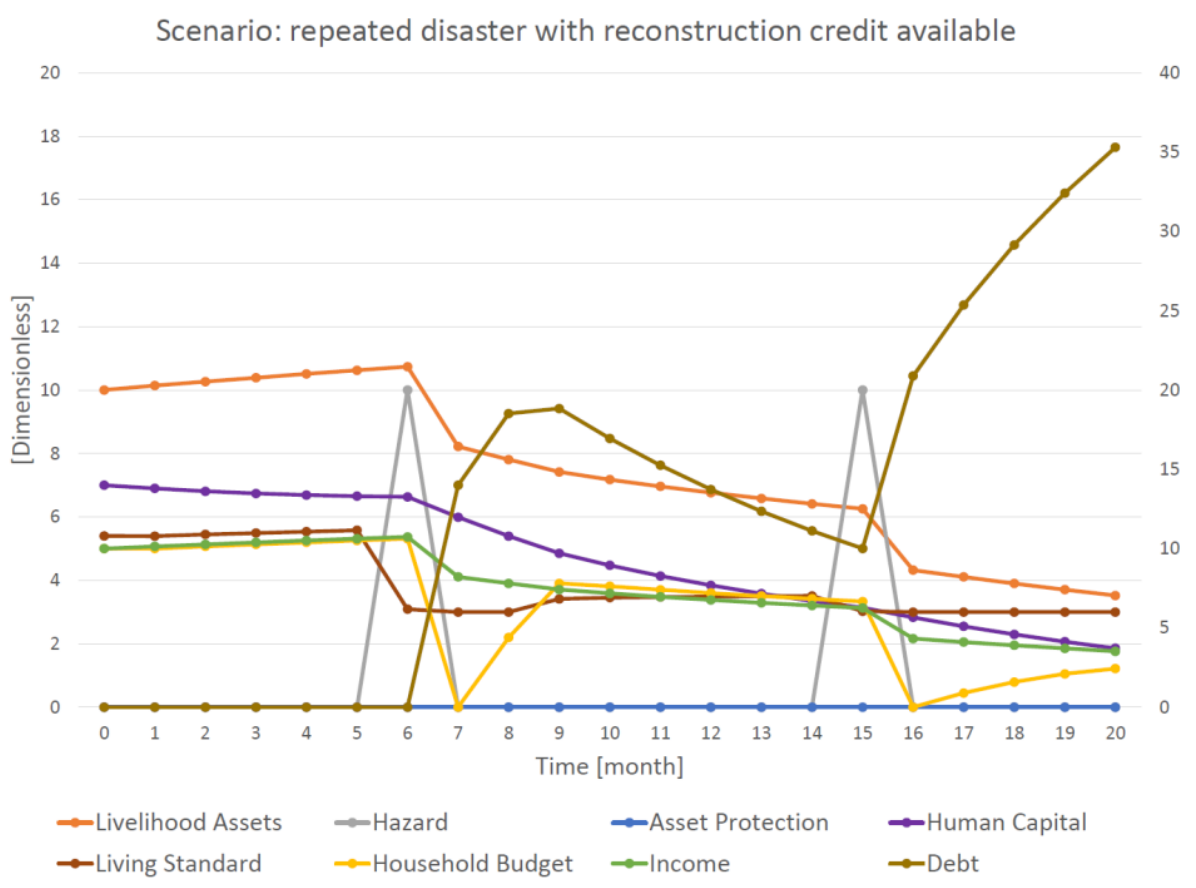

c) Repeated Disasters with Reconstruction Credit Available

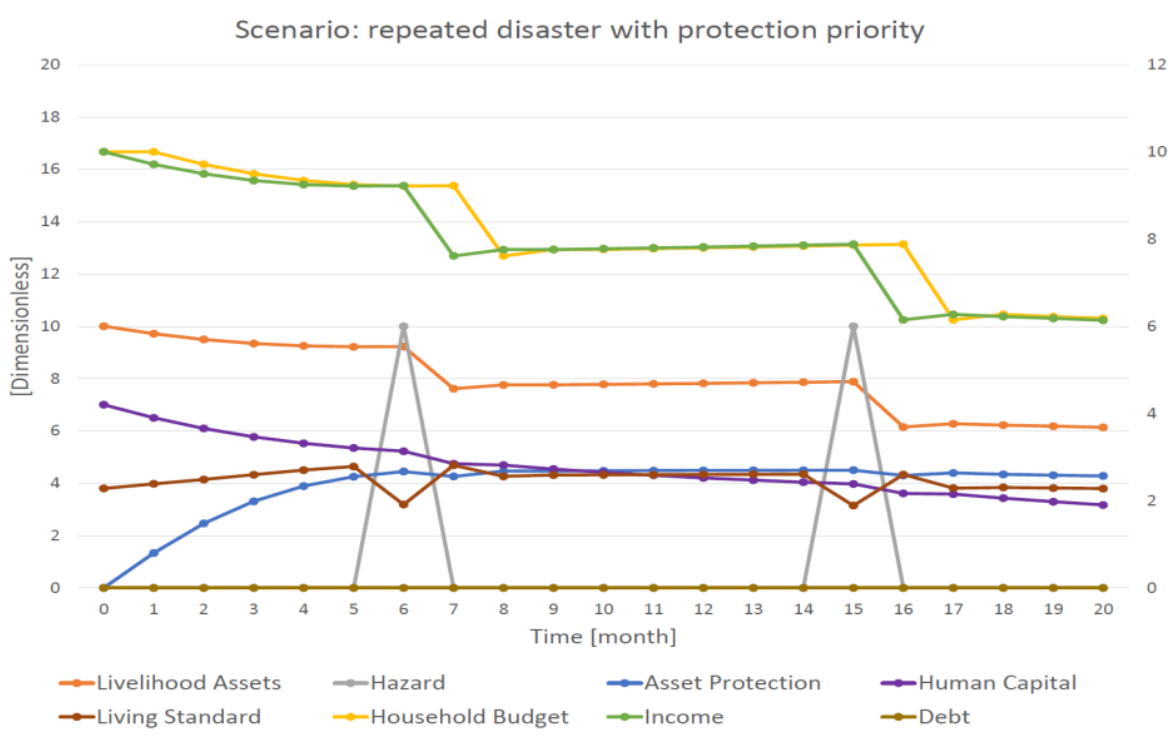

\section{d) Repeated Disasters with Stronger Priority on Protection Measures}

Figure 5. Model results (different scenarios). The time axis represents months. The variables on y axis (livelihood assets, hazard, asset protection, human capital, household living standard, household budget, household income, household debt) are represented as dimensionless indices. The initial conditions are set to represent a low-income household but not in crisis. The interpretation should focus on trends and relative proportions of the variables as well as ratios between the variables rather than specific individual values. The model results provide an insight into emerging dynamical patterns and is not build with purpose of predicting specific values of individual variables. 
Single disaster results (Figure 5a) show the irreversible (within the model time frame) reduction of income, human capital and living standard. After the disaster (month 6) the income assets are damaged, which leads to reduced income. Lower budget makes it harder to meet basic needs and services needed, leading to a long-term reduction of the household financial and human potential.

Repeated disaster (Figure 5b) leads to complete household collapse eliminating source income. In this scenario, the household, that is weakened with the first disaster scenario, is hit again with another disaster in month 15 , which leads to the death spiral. Both this and single disaster scenario does not include any community or outside support that may be available for households in such difficult situations.

Adding availability of reconstruction credit (Figure 5c) improves the situation preventing household decline, however it is done at a cost of increasing debt. After disaster credit for reconstruction becomes available, the decline of livelihood assets is reduced, keeping household income higher than in the "repeated disasters" scenario. At the same time, household expenditures increase due to the debt and interest payments. This manifests after the second disaster when debt starts increasing in an uncontrolled way. In the real world there are probably stronger limits to available credit that would reduce household capacity to satisfy basic needs and sustain livelihoods.

Early investment in protection measures (Figure 5d) is the most favorable scenario with an assumption of recurring hazard events. This scenario demonstrates the importance of prevention. When investments in assets protection are given higher priority, it results in lower exposure, in effect reducing potential damage. As a consequence, when disaster hits, damage of livelihood assets is less severe with lower impact on livelihoods. It allows the household to continually receive substantial income and even the second disaster, although imposing further strain, does not lead to a collapse. In reality, prevention expenditures are not easy to justify as they compete with more essential (as perceived by a household) spending.

It is important to note that exploring different scenarios with the proposed model should only be a part of wider, participatory processes engaging all relevant stakeholders. As the values in the model are stylized, one of the challenges is to adjust them to represent real-life conditions, which should be done in a deliberative manner. Thus, the system dynamics model is only a starting point for discussion with local communities on the possibilities of improvement of their flood resilience.

\subsection{Flood Resilience Game - Engaging Stakeholders In Understanding And Planning How To Improve Flood Resilience In Their Communities}

There is growing interest in using serious games and social simulations among the disaster risk management community (Solinska-Nowak et al. 2018), with applications ranging from disaster response planning and training activities before the real crisis occurs (Walker 1995); effective risk communication orienting for participatory risk management with a diverse set of stakeholders (Yamori 2011); to embedding the cultural aspects (diversity, cultural memory) in disaster risk management (Kulakowska et al. 2017).

The term "serious games" (Aldrich 2009) is used to describe gaming activities designed for purposes other than entertainment, such as training, education, or social change (Ratan and Ritterfeld 2009). The roots of this approach come from game theory, drama theories, and systems analysis. Social simulations are a multiplayer, workshop-oriented type of serious 
games (Solinska-Nowak et al. 2018). Participants takes on certain roles in shared environment which rules represent the key aspects of the real world. They experience challenges resulting from multiple perspectives that they all bring to the table and experiment with a problem situation. By facing consequences of their decisions, they come up with improved strategies (Solinska-Nowak et al. 2018; Duke and Geurts 2004).

Serious games and social simulations aim to improve understanding of a complex issue (Duke 1974), given that they can act as metaphors reflecting specific systems (Mendler de Suarez et al. 2012), and that they can employ "procedural rhetoric" - "the practice of using processes persuasively" (Bogost 2007). What is more, role-playing aspects of games foster individual initiative and imagination (Ladousse 1987). The inclusive and open character of games and simulations allows even stakeholders without relevant background to engage in highly complex decisions (Stefanska et al. 2011).

\section{Flood Resilience Game and FLORES framework}

The Flood Resilience Game is a social simulation that allows players to experience, explore, and learn about the flood risk and resilience of communities in river valleys. The game is set in a community living in an area exposed to floods, occurring with different severity.

Players take roles of members of different citizen groups, local government and water board officials. Each round, players can learn and perform specific Flood Resilience Actions, based on the Zurich Flood Resilience Measurement tool (Szoenyi et al. 2016). Flood Resilience Actions increase flood resilience for specific citizens or the whole community.

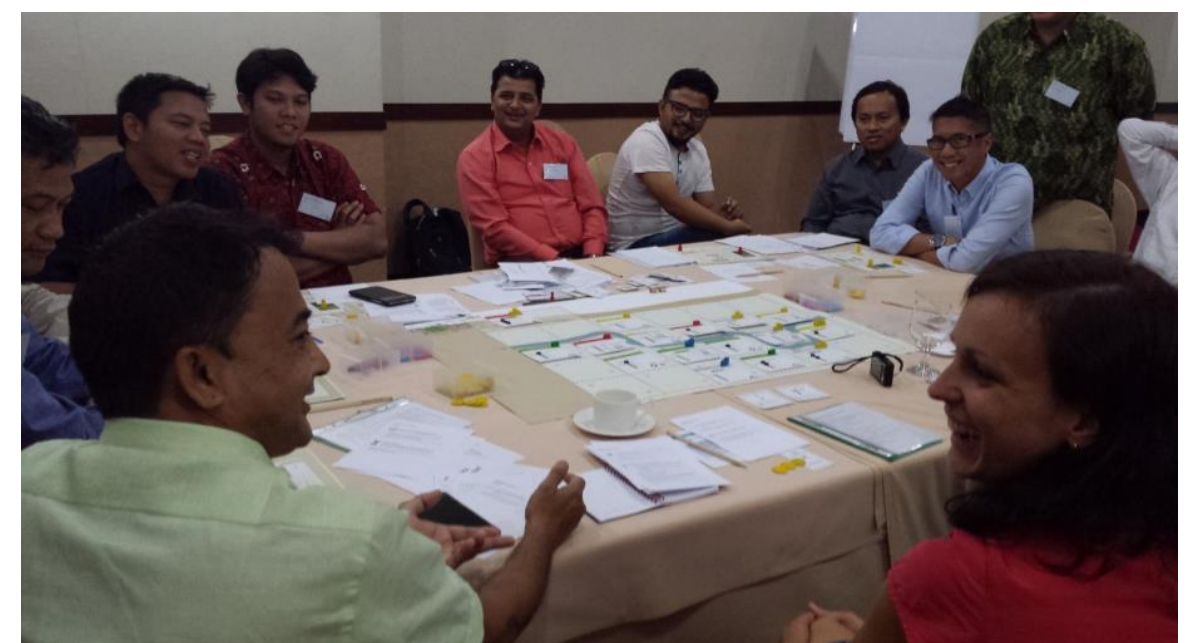

Figure 6. A session of the Flood Resilience Game in Jakarta, Indonesia. (Photo: Adriana Keating)

The game aims to be an exercise in both short- and long-term decision-making under flood risks, working as a starting point for mutual learning for communities and flood professionals, igniting a meaningful discussion on what works, and for whom (Jarzabek 2016). As such, it works as an experiential tool to introduce participants to FLORES. Most of the framework's elements and interconnections are represented in the game. More in-depth mechanisms of the game are based on the qualitative model of community flood resilience built on FLORES (see section 4.1 of this article). 
The in-game community is, echoing the framework, exposed to flood hazard. Floods create risk of damages to the buildings, assets, and infrastructure, represented by the cards that are placed on the game board. The game board is divided into a number of parcels, in a stylized manner representing spatial location. The land use of each parcel is defined by the buildings, assets, and infrastructure cards that are placed on them. Defense infrastructure - levees - to some point can decrease the flood severity, however, bigger floods can damage it. Physical vulnerability - the condition of specific buildings, assets, and infrastructure affects the risk of damage to them, as well as their spatial location and land use: the parcels have different flood risk levels. All of this contributes to the representation of the community's physical capital in the game. Drawing further from the qualitative model, the game distinguishes private houses and physical assets used by citizens to generate income; and different types of public infrastructure that provide services for the community (water supply, food market, health clinic, school, irrigation system, power station, road to a bigger city; in the Valladolid version also waste management and sanitation).

Investments in physical capital affect the physical vulnerability the buildings, assets and infrastructure: the damage level depends on the flood severity on particular plot, but also the building/infrastructure development level, or protection measures taken earlier.

Physical capital, as in the FLORES framework, is connected with livelihoods of the in-game community. Livelihoods are represented in the form of variety of jobs and local businesses that bring income to game participants, with simplified representation of markets also present. Jobs, businesses and markets depend on services provided by infrastructure. Livelihoods can be affected by losses caused by the indirect effects of floods. Livelihoods impact the quality of life of individual households, that is represented by the condition of their houses, and fulfilling basic needs and providing food and water must be secured by the game participants each round. The qualitative model was used to elaborate the relations between physical capital, livelihoods, and quality of life. The players have jobs in a remote big city (workers) or make a living from agriculture, having small farms (farmers); there is also local entrepreneur, and financial services vendor. Livelihoods and quality of life depend closely on the services provided by the infrastructure, and also on the condition of citizens' assets: for example, the price of food and water that citizens buy depends on the state of the infrastructure (food market and water supply) and grows when floods damage this infrastructure (making food and water harder to get). Health level is affected by fulfilling basic needs and by flood accidents. The impact of flood accident depends on the access to the health clinic, which is limited and costs more when the clinic is flooded. Household budget, with savings and debt, impacts the quality of life of citizens, as funds are needed for fulfilling the needs, health reparation, house maintenance, and investing in education.

Both in the framework and in the game, human, social, financial, and natural capitals create the capacity for reducing risk of damages through corrective risk reduction and crisis preparedness, restore physical capital through reconstruction, and reduce losses through response and rehabilitation. Particular actions that players can take in the game can be placed in different phases of the DRM cycle included in the FLORES framework. An important aspect that the game omits at this point is prospective risk reduction (avoiding risk creation).

Following the framework, knowledge, skills, and risk perception as recognized as parts of human capital in the game. They create capacity for crisis preparedness (as citizens can learn new skills that can be critical when the flood hits (e.g. first aid, evacuation drill), and as their knowledge on possible actions they can they grows during the course of the game); and 
corrective risk reduction (Water board plays important role here, disseminating the knowledge about the flood risk of particular plots).

Both in the FLORES framework and in more detailed model based on it, social capital creates capacity for performing actions connected with disaster risk management. The game elaborates further on that aspect. Social relations include neighbor relationships, but also inequalities, as initial conditions of the game are different for each player. Government create policies and communicate them (or not) to other players. All of this, together with the variety of the available actions, and with the worldviews, aspirations, and goals that players enter the game with, simulates complex social relations. Social capital also emerges during the game, e.g. in the form of informal institutions created by the players (coalitions of players, creating rules of investment or mutual support, or even organizing the communication process). Open character of the game's social layer catalyzes such creativity. Social capital creates capacity for: crisis preparedness (as local government and water board spread disaster awareness); reconstruction and response/rehabilitation (mutual help between the citizens that lowers the costs of reconstruction after the flood; similar thing does the common reconstruction budget established by local government).

On the level of framework, financial capital includes emergency funds and insurance. Emergency funds are available for players both as formal actions (savings, emergency fund created by local government), and as mentioned before informal funds created by players. In the model, financial capital on the individual level is defined through the wealth and savings that each citizen can amass, or debt that they can get into. As the actions demand investment, it creates capacity for corrective risk reduction, crisis preparedness, reconstruction, and response/rehabilitation.

On the community level, aside the budget of local government and water board, there are actions that the whole community can contribute to: financing insurance for the critical infrastructure and establishing flood reconstruction budget. Players can also get loans (both banking - from the financial services vendor and informal - from other players). Local government and Water board can also support each other, and also the citizens.

Natural capital is represented in the game by areas that in the long run can be used for risk reduction through upstream reforestation that decreases flood intensity, creating capacity for corrective risk reduction. The natural capital aspect will be developed further in the future versions of the game, to include also aspects of ecosystem services impact on livelihoods.

The game strongly highlights the development aspect that, as in the FLORES framework, affects all five capitals and livelihoods. On the smaller scale, is represented through the ability of citizens to invest in improvement of their houses. On the bigger scale, citizens and officials can invest in improvement of infrastructure. Improving houses and infrastructure is costly, however, in the long run, it leads to generating less costs, and more effective performance. Specific policies, rules, and programs are not formalized in the game and emerge during the gameplay.

\section{Applications of the Flood Resilience Game}

The game was run in Jakarta, Indonesia with the participants recruited from the staff of Zurich Indonesia and a number of non-governmental organizations: Red Cross Indonesia, the International Federation of Red Cross and Red Crescent Societies, Mercy Corp, Plan and Concern Worldwide. While most of the participants fared well during the game, there were 
some players that needed help, with one participant going bankrupt. Lack of grassroots initiatives was characteristic for the "community meeting" held during the game, with most of the participants playing as citizens expressing top-down attitude in the relations with the players taking the roles of the government agendas. At the end of the game session, the participants managed to decrease flood risk using flood retention pond scheme action.

The game was also applied in Lima, Peru by Practical Action Latin America (Soluciones Prácticas). The participants were recruited from community leaders and local authorities coming from different geographic areas. The participants focused mostly on implementing the DRR measures and maintaining their health indicators, while some of them deliberately decided on not investing in education. They also appreciated the possibility of testing different solutions and learning from mistakes. The differences between how water distribution process was portrayed in the game and how it is organized in Peru were challenged by some of the participants, stressing out the need for increasing the game's flexibility in terms of adapting it to particular local conditions.

A modified version of the game was applied in Valladolid, Spain, as part of a capacity building workshop pursuing to create awareness on flood risk and strengthen the intercommunication and information pathways amongst the main flood risk management stakeholders and vulnerable groups. The game was played during a pilot case study within the Horizon 2020 EDUCEN project, aimed to build on existing European networks and identify actions to support the potential of culture and cultural diversity for disaster risk reduction.

The players, recruited from the aforementioned stakeholders, went through the three DRM phases (preparation phase, flood event/crisis phase and post-crisis or recuperation phase) for five game rounds during which different individual and group decisions had to be made to protect the three central pillars directly or indirectly affected by the flood as represented in the FLORES framework: physical capital (buildings, assets and infrastructure, and related functions), livelihoods (businesses, jobs, markets translating into income and services) and ultimately quality of life (coverage of basic needs, e.g. water, food, housing or access to education).

Several strategies to trigger institutional settings and decisions that would facilitate collective risk reduction and protection were discussed. These spanned actions to promote the financial capital (emergency investments and funds, tax exemptions, collaborative funding), the social capital (agent associations, community generosity towards vulnerable actors), the human capital (increased skills and awareness through experience learning and information) and, to a lesser extent, the natural capital (value of ecosystem functions and buffering power against floods). By the end of the game, the progressive display of individual and collective protection measures had reduced the overall vulnerability of the community as well as the magnitude of the impacts of successive flood events. However, this came at the expense of renouncing to certain levels of wellbeing by some of the civil society roles. After completion of the game, the participants were asked to provide insights and lessons learned from the experience that were summarized in a list of key highlights.

First, there is an extremely high level of interconnection and interdependence amongst all actors, which brought forward the importance and impact of inclusive inter-collaboration and negotiations beyond individual or top-down actions. Second, the existence of a tradeoff between self-protection and life quality brings the need to make difficult decisions and prioritize when making income investments. Third, whereas the decision-making process at the individual level is not easy, collective decision making involving all the actors and seeking consensus leads to more efficient processes and effective results. Furthermore, it can buffer 
this self-protection/life quality tradeoff avoiding the need for sacrifices and life quality losses amongst the most vulnerable actors. Fourth, there was a consensual acknowledgement about the lack of awareness and underestimation of the potential of the Natural Capital to buffer flood impacts, which leads to a prioritization and overreliance on infrastructural based solutions (such as dams). As a final remark, the participants highlighted the usefulness of the game to understand the cycle and process of flood risk management, the roles and influence from different type of actors and how knowledge and capacities can make a difference, and the range of possible tools and strategies to reduce the vulnerability against flood risks.

For comparative analysis of game applications' results, please also see Appendix D. Comparison of game applications.

\subsection{From serious gaming to serious decision-making: a role for forensics-informed scenarios}

The FLORES framework was tested and refined in a multi-stakeholder workshop targeted at conceptualizing the linkages between flood-related disasters and development. This workshop included risk management-focused NGO practitioners and public sector and civil society representatives in Lima, Peru and its peri-urban outskirts. By highlighting a variety of direct and indirect connections between local to national-scale development processes and disaster outcomes, this exercise illustrated the potential of the FLORES framework to systematize important dynamics within specific empirical cases.

This empirical application of the FLORES framework is particularly relevant in a context like that of Peru, where disaster risk management has long been dominated by short-term emergency preparation and post-event ad-hoc response to individual disasters. Discussion of the varied components of the framework aided in identifying both underlying physical and socio-economic drivers of exposure and vulnerability and their interactions and feedbacks (e.g. between exposure to severe flooding, lack of zoning regulations and enforcement, informal land settlement patterns, and corruption and political clientelism). Additionally, the framework aided in expanding some stakeholders' conceptions of development to include institutional innovation and related elements of social and human capital.

Building on the stakeholder interactions, further expert interviews and forensics investigation into the drivers of flood risk and impacts (such as experienced through the recent El Nino event in 2016/17), the FLORES framework and systems approach can be utilized to develop dynamic risk and resilience narratives and associated scenarios (Figure 7). A 'business-as-usual' scenario characterized by reactive risk reduction would lead to strong increases in (flood) risk (asset exposure growth coupled with climate change induced modifications of rainfall and flood); implementing actions aligned with a scenario of 'engineered safety' dominated by corrective risk reduction would likely lead to substantial risk reductions. Yet, in the face of substantial uncertainty (role of climate change driving risk, future exposure increases and changes in vulnerability), only a scenario of 'resilience under uncertainty' that would demand and integrative DRR approach across local to national scales and across sectors coupled with a strong commitment to prospective DRR through enforcing hazard-zoning regulations and relocation processes would be sufficient to truly arrest future expect increases in risk (see French and Mechler2017). 


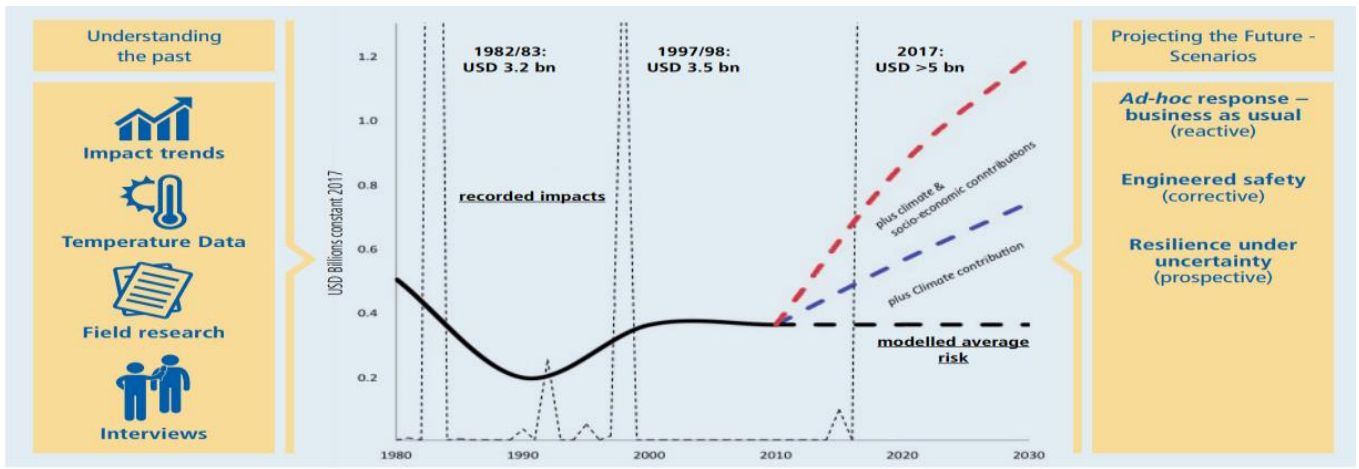

Figure 7. Dynamic risk and resilience analyses use historical data of impact trends (black line) and other input variables (left side) to build projections of future scenarios of risk management and resilience (right side) in Peru (colored dotted lines). (Source: French and Mechler 2017)

While none of the scenarios will exactly see the light of day, scanning the future horizon with systems-based narratives and scenarios provides a projection space for envisioning the consequences of potential actions, and thus support further deliberations on how to tackle risks.

\section{DISCUSSION AND CONCLUSIONS}

Recent years have brought the shift in perception of how disaster risk and development are interconnected. State of the art documents in the disasters field (UNISDR 2015; United Nations 2015) propose embedding disaster risk reduction within development efforts: as the part and consequence of development, rather than external threats to development gains. Such framing of disaster risk results in the need for holistic, systems approach that integrates both disasters and development perspectives.

The concept of resilience, becoming increasingly prominent in the disasters field, offers a systems perspective through which the interconnections between disasters and development can be examined. There are multiple definitions of disaster resilience, with different focuses.

A development-centered definition of disaster resilience that brings forward resilience of community wellbeing (rather than resilience of the system supporting and promoting community wellbeing, as opposed a narrower approach focused on managing a risk), is "the ability of a system, community or society to pursue its social, ecological and economic development objectives, while managing its disaster risk over time in a mutually reinforcing way" (Keating et al. 2017).

Flood Resilience System (FLORES) framework draws from the development-centered definition of disaster resilience. Responding for the need of integrating disasters and development fields, FLORES combines parts of other existing frameworks from both disciplines: Disaster Risk Management (DRM) cycle, the five capitals (social, physical, human, financial, natural) from the Sustainable Livelihoods framework, and analyzing economic conditions of households from the Household Economy Approach framework. FLORES can be used as a standalone tool supporting communities, decision makers, and policy makers in conceptualization of the interconnections between disaster and development. While it was created based on flood hazards, it can be also applied in the context of other disasters. FLORES 
is also a basis for a number of other tools that explore community resilience on different levels: from abstract models to empirical research. These tools are presented in this paper.

The qualitative system dynamics model described in section 4.1 elaborates specific parts of FLORES (e.g. financial capital aspect), also providing more in-depth causal relationships between particular elements of the framework, and adding simple variables. The model presented in this paper is an example how such model can be built using FLORES: depending on the need, other models can be constructed, focusing on other aspects of the framework, or on representing other relationships, elements, and variables that are specific for, e.g., particular geographical setting or governance level (local, regional, national, etc.) that is to be represented by the model. Such qualitative models can be also a first step in developing more advanced tools: quantitative models and simulation games.

The stylized dynamic model described in section 4.2 builds on the qualitative model, focusing exclusively on the households' aspect of FLORES. The model is quantitative, representing real-life proportions between stylized values. Such model can be further customized with input from the stakeholders, in order to better suit specific application needs. There is a possibility of further development of the presented model with other aspects of FLORES besides households.

The social simulation game described in section 4.3 uses the whole FLORES framework as the conceptual basis, and also employs the qualitative system dynamics model to define the relationships between particular game elements in more detailed manner. Using the game demands more time and effort than exploring different scenarios with a model, however, it allows to uncover the aspects of a problem that are hidden from modelers but are known to the stakeholders. The game enables a broader range of stakeholders to get involved in the deliberation process, as it is designed for engaging participants that are both trained and nontrained in the subject matter. Employing a simulation game is more empirical approach: it enables the participants to get insight on how whole system works, how its particular parts and subsystems are interconnected. In effect, such simulation game can be a first step in wider participatory process in which stakeholders deliberate how to integrate disaster risk management and development in their particular context. As many of leverage points lie outside the community level, optimal setting for social simulations is when participants recruit from not only community members, but also decision makers and policy makers. This is beneficial for all sides of such process: while the officials gain insight on the impacts of their decisions on community level, the community members learn how the decisions are made in the broader system that their community is part of.

The applications of FLORES described in section 4.4 showed the framework's potential to systematize important dynamics within specific empirical cases. The discussion on specific elements of framework allowed both stakeholders and researchers to better understand local situation. The empirical application of the framework showed its potential as a basis for developing different risk and resilience narratives and scenarios. Such narratives and scenarios can be further employed to support participatory discussion on community resilience.

Up to date applications of FLORES show the potential of employing the framework in wide range of efforts aimed at understanding and increasing community flood resilience. The tools that are based on or use the framework are complementary, for example, while stylized quantitative model can be used for theoretical exploration of different scenarios, a simulation game can be employed to get input from the stakeholders on their realities, and thus be used as a starting point for further discussion leading to an in-depth analysis of local situation. Together, this creates a range of methods that, when used in a participatory, locally-oriented 
manner, have a chance for sparking a deliberative process that will contribute to actual increasing of community resilience.

\section{REFERENCES}

Adger, W. N. (2006) Vulnerability. Global Environmental Change, 16 (3): 268-281.

Adger, W. N., Hughes, T. P., Folke, C., Carpenter, S. C., and Rockström, J. (2005) SocialEcological Resilience to Coastal Disasters. Science, 309 (5737): 1036-1039. DOI: $10.1126 /$ science. 1112122

Aldrich, C. (2009) The Complete Guide to Simulations and Serious Games. San Francisco: Pfeiffer.

Beck, U. (1992) Risk Society: Towards a New Modernity. New Delhi: Sage

Béné, C. , Newsham, A. , Davies, M. , Ulrichs, M. and Godfrey- Wood, R. (2014) Review Article: Resilience, Poverty, and Development. Journal of International Development, 26: 598-623. doi:10.1002/jid.2992

Bertsche, D., Crawford, C., and Macadam, S. E. (1996) Is simulation better than experience? The McKinsey Quarterly, 1: 50-57.

Bogost, I. (2007) Persuasive games. The Expressive Power of Videogames. Cambridge, London: The MIT Press.

Brown, S. (2015) Peru Livelihood Baselines Profiles Using the Household Economy Analysis. Practical Action.

Bruneau, M., Chang, S. E., Eguchi, R. T., Lee, G. C., O’Rourke, T. D., Reinhorn, A. M., Shinozuka, M., Tierney, K., Wallace, W. A., and von Winterfeldt, D. (2003) A Framework to Quantitatively Assess and Enhance the Seismic Resilience of Communities. Earthquake Spectra, 19 (4): 733-752.

Cañas, A.J., Carff, R., and Hill, G. (2005) Concept maps: integrating knowledge and information visualization. In: Tergan, S.-O., Keller, T. (eds), Knowledge and information visualization. Heidelberg: Springer: 205-219.

Carpenter, S. R., Walker, B., Anderies, J. M., and Abel, N. (2001) From Metaphor to Measurement: Resilience of What to What? Ecosystems, 4: 765-781.

Coutu, D. L. (2002) How Resilience Works. Harvard Business Review, May: 46-55.

DFID (2001) Sustainable Livelihoods Guidance Sheets. Department for International Development

Duke, R.D. (1974) Gaming: the future's language. New York: Halstead Press.

Duke, R.D., and Geurts, J.L.A. (2004) Policy games for strategic management. Amsterdam: Dutch University Press.

Fabinyi, M., Evans, L., and Foale, S.J. (2014) Social-ecological systems, social diversity, and power: insights from anthropology and political ecology. Ecology and Society, 19 (4): 28.

Folke, C. (2006). Resilience: The emergence of a perspective for social-ecological systems analyses. Global Environmental Change, 16 (3): 253-267. 
French, A. \& Mechler, R. (2017). Managing El Niño Risks Under Uncertainty in Peru: Learning from the past for a more disaster-resilient future. International Institute for Applied Systems Analysis , Laxenburg, Austria. Author (2017)

Gunderson, L. (1999) Resilience, flexibility and adaptive management: antidotes for spurious certitude. Conservation Ecology, 3 (1): 7. [online] URL: http://www.ecologyandsociety.org/vol3/iss1/art7/.

Gunderson, L. H. (2003) Adaptive dancing: interactions between social resilience and ecological crises. In: F. Berkes, J. Colding, and C. Folke, (eds.). Navigating socialecological systems: building resilience for complexity and change. Cambridge University Press, Cambridge, UK., pp. 33-52.

Hamel, G., and Välikangas, L. (2003) The Quest for Resilience. Harvard Business Review, September: 52-63.

Hochrainer-Stigler S, Desai B, Keith W, Maskrey A, Mechler R, \& Mochizuki J (2017). Risk-sensitizing Future Investment Needed to Achieve the Sustainable Development Goals. International Journal of Disaster Risk Reduction, 24: 482-484.

Holling, C. S. (1973) Resilience and Stability of Ecological Systems. Annual Review of Ecology and Systematics, 4: 1-23.

Holzmann, P., Boudreau, T., Holt, J., Lawrence, M. and O'Donnell, M. (2008) The Household Economy Approach. A guide for programme planners and policy-makers. FEG Consulting and Save the Children.

Horne, J. F. (1997) The Coming Age of Organizational Resilience. Business Forum, 22(23):24-28.

Jarzabek, L. (2016) How game can help flood-prone communities. [online:] https://games4sustainability.org/2016/08/18/flood-resilience-game-for-flood-pronecommunities/Author (2016)

Kahneman, D. (2011) Thinking, Fast and Slow. New York City: Farrar, Straus and Giroux.

Keating, A. , Campbell, K. , Mechler, R. , Magnuszewski, P. , Mochizuki, J. , Liu, W. , Szoenyi, M. and McQuistan, C. (2017) Disaster resilience: what it is and how it can engender a meaningful change in development policy. Development Policy Review, 35: 65-91. doi:10.1111/dpr.12201

Keating, A. and Hanger, S. 'Practitioner Perspectives of Disaster Resilience in Theory and Practice' under review.

Klinke, A., \& Renn, O. (2002). A New Approach to Risk Evaluation and Management: Risk- Based, Precaution- Based, and Discourse- Based Strategies 1. Risk Analysis: An International Journal, 22 (6): 1071-1094.

Kulakowska, M., Solinska, A., Pajak, M., Jarzabek, L., and Magnuszewski, P. (2017). Using games to connect culture and disaster. In: EDUCEN Culture \& Urban Disaster. A Handbook.

Ladousse, G. P. (1987) Role Play. Oxford: Oxford University Press.

Linnerooth-Bayer, J., Mechler, R., \& Pflug, G. (2005). Refocusing disaster aid. Science, 309 (5737): 1044-1046. 
Magnuszewski, P. (2010) Systems thinking. In: Challenges of Sustainable Development in Poland. Sendzimir Foundation: Krakow.

Manyena, B., O'Brien, G., O'Keefe, P., snd Rose, J. (2011) Disaster resilience: a bounce back or bounce forward ability? Local Environment: The International Journal of Justice and Sustainability, 16 (5): 417-424.

McQuistan, C. (2015). Why Technology Justice is Critical for the Climate Negotiations. Delivering on Loss and Damage. Technology Justice Policy Briefing 4. Practical Action, Rugby, UK.

Mechler, R, McQuistan, C, McCallum, I, Liu, W, Keating, A, Magnuszewski, P, Schinko, T, Szoenyi, M and F Laurien (2018) Supporting climate risk management at scale. Insights from the Zurich Flood Resilience Alliance partnership model applied in Peru \& Nepal in: Mechler, R, Bouwer, L, Schinko, T, Surminski, S, Linnerooth-Bayer, J. (eds) Loss and Damage from Climate Change. Concepts, Methods and Policy Options. Heidelberg: Springer.

Mendler de Suarez, J., Suarez, P., and Bachofen, C. (eds) (2012) Games for a New Climate: Experiencing the Complexity of Future Risks. Boston: The Frederick S. Pardee Center for the Study of the Longer-Range Future, Boston University.

Novak, J.D., and Cañas, A.J. (2006) The theory underlying concept maps and how to construct them. Pensacola, FL: Florida Institute for Human and Machine Cognition.

Olsson, P., Gunderson, L. H., Carpenter, S. R., Ryan, P., Lebel, L., Folke, C., and Holling, C. S. (2006) Shooting the rapids: navigating transformations to adaptive governance of social-ecological systems. Ecology and Society, 11 (1): 18. [online] URL: http://www.ecologyandsociety.org/vol11/iss 1/art18/.

Paton, D., and Johnston, D. (2001) Disasters and communities: vulnerability, resilience and preparedness, Disaster Prevention and Management: An International Journal, 10 (4): 270-277. https://doi.org/10.1108/EUM0000000005930

Ratan, R.A.., \& Ritterfeld, U. (2009). Classifying serious games. In Serious games (pp. 3246). Routledge.Rydzak, F., Magnuszewski, P., Sendzimir, J., and Chlebus, E. (2006) A concept of resilience in production systems. In Proceedings of the 24th International Conference of the System Dynamics Society (pp. 1-26).

Scoones, I. (1998). Sustainable rural livelihoods a framework for analysis. IDS working paper 72 .

Sen A. (1981). Poverty and Famines: An Essay on Entitlement and Deprivation. Oxford: Clarendon Press

Sendzimir, J., Magnuszewski P., Flachner, Z., Balogh, P., Molnar G., Sarvari A., and Nagy Z. (2007). Assessing the resilience of a river management regime: informal learning in a shadow network in the Tisza River Basin. Ecology and Society, 13 (1): 11. [online] URL: http://www.ecologyandsociety.org/vol13/iss1/art11/ [accessed March 2018]

Solinska, A., Magnuszewski, P., Steenbergen, M., French, A., Keating, A., Mochizuki, J., Liu, W., Mechler, R., Kulakowska, M., and Jarzabek, L. (2018) An overview of serious games for disaster risk management - prospects and limitations for informing actions to arrest increasing risk. International journal of disaster risk reduction, 31, 1013-1029. 
Stefanska, J., Magnuszewski, P., Sendzimir, J., Romaniuk, P., Taillieu, T., Dubel, A., Flachner, Z., and Balogh, P. (2011) A Gaming Exercise to Explore Problem-Solving versus Relational Activities for River Floodplain Management. Environmental Policy and Governance, 21 (6): 454-471.

Sterman, J.D. (2000) Business Dynamics. System Thinking and modelling for a complex world. Irwin/Mc Graw-Hill, Boston.

Szoenyi, M., Nash, D., Bürer, M., Keating, A., McQuistan, C., and Campbell, K. (2016) Risk Nexus Measuring flood resilience - our approach. Zurich Insurance Group Ltd.

UNISDR (2015) Global Assessment Report on Disaster Risk Reduction - Making Development Sustainable: The Future of Disaster Risk Management, United Nations Office for Disaster Risk Reduction, Geneva, [online] http://www.preventionweb.net/english/hyogo/gar/2015/en/gar-pdf/GAR2015_EN.pdf [accessed March 2018]

United Nations (2015) Sendai Framework for Disaster Risk Reduction 2015-2030, 18 March 2015, A/CONF.224/CRP.1, [online:] http://www.wcdrr.org/uploads/Sendai_Framework_for_Disaster_Risk_Reduction_20152030.pdf [accessed March 2018]

Walker, B. H, Holling, C. S., Carpenter, S. C., and Kinzig, A. P. (2004) Resilience, adaptability and transformability. Ecology and Society, 9 (2): 5. [online] URL: http://www.ecologyandsociety.org/vol9/iss2/art5/.

Walker, B., \& Salt, D. (2012). Resilience thinking: sustaining ecosystems and people in a changing world. Island press.

Walker, B., Carpenter, S., Anderies, J., Abel, N., Cumming, G., Janssen, M., Lebel, L., Norberg, J., Peterson, G. D., and Pritchard, R. (2002) Resilience management in social ecological systems: a working hypothesis for a participatory approach. Conservation Ecology, 6 (1) (Article 14).

Walker, W. E. (1995) The Use of Scenarios and Gaming in Crisis Management Planning and Training. Santa Monica: RAND.

World Bank and United Nations (2010) Natural hazards, unnatural disasters: the economics of effective prevention. World Bank, Washington, DC.

Yamori, K. (2011) The Roles and Tasks of Implementing Science on Disaster Prevention and Reduction Knowledge and Technology: From Efficient Application to Collaborative Generation. Conference on Integrated Disaster Risk Management (IDRiM). University of Southern California, Los Angeles, 14-16 July. 